Original Research Paper

\title{
Modeling and Performance Analysis of a Petroleum-Pipeline- Pressure-Boosting Station Powered by Two-Shaft GT Engine
}

\author{
Yousef S. H. Najjar, Mohammad Z. M. Yousef and Aad M. A. Al-Mahgari \\ Department of Mechanical Engineering, Jordan University of Science and Technology, Irbid, Jordan
}

\author{
Article history \\ Received: 01-05-2021 \\ Revised: 06-05-2021 \\ Accepted: 18-05-2021 \\ Corresponding Author: \\ Yousef S. H. Najjar \\ Department of Mechanical \\ Engineering, Jordan University \\ of Science and Technology, \\ Irbid, Jordan \\ Email: y_najjar@hotmail.com
}

\begin{abstract}
This study offers modeling and performance analysis of a pressure-boosting station for petroleum pipelines using a sustainable two-shaft GT engine to drive a three-stage centrifugal pump. The modeling is divided into three steps; matching the GT engine components at the maximum efficiency line, matching the pump performance with the requirements of the pipeline system to generate the pump load curve, then matching the pump load curve to the GT engine power-speed curve at the maximum efficiency to study the plant's overall performance. At design point, the GT engine efficiency was $37.5 \%$ while the station net pumping-power output was $\sim 2 \mathrm{MW}$ with an overall efficiency of $\sim 30 \%$ and Specific Fuel Consumption (SFC) of $\sim 0.217 \mathrm{~kg} / \mathrm{kWh}$. Also, the effect of varying the GT engine compression ratio $\left(r_{c}\right)$ on the plant's performance parameters, i.e., SFC, efficiency and power output were thoroughly examined, revealing that the compressor turbine range was the most limited and that the part-load efficiency of GT engine at $50 \%$ power-output loading was $32.2 \%$. Finally, sensitivity analysis was performed to find that for each $10 \%$ drop in $r_{c}$, the station overall efficiency drops by only $6.5 \%$.
\end{abstract}

Keywords: Petroleum Pipelines, Oil and Gas Transport, Two-Shaft Gas Turbine Modeling, Heat Exchange Cycle, Free-Power Turbine and PressureBoosting Station

\section{Introduction}

With the continuous rise of global population and the booming in urban and industrial development, the demand for energy is growing faster than ever. According to International Energy Agency (IEA), Oil and natural Gas $(\mathrm{O} \& \mathrm{G})$ will continue to dominate the energy market at least for the first half of the $21^{\text {st }}$ century despite the rising contribution of renewables, driven by stern environmental concerns (Hart, 2014). Moreover, the limitations and low market competitiveness of renewables make other approaches necessary. This include waste heat utilization through adopting various configurations (Akyurt et al., 1995; Barigozzi et al., 2015) to improve the efficiency and reduce $\mathrm{CO}_{2}$ emissions.

On the other hand, one of the major aspects of $\mathrm{O} \& \mathrm{G}$ industry, beside production, is transporting the product over large distances using safe, less polluting and economically effective methods. Previous studies concluded that transporting O\&G by tankers consumes large amounts of energy and contributes to increasing greenhouse gas levels. Therefore, using pipelines for $\mathrm{O} \& \mathrm{G}$ transporting has been proven to be safer, faster, cheaper and more sustainable (Wang et al., 2019; Guo et al.,
2016). Pipelines are used to carry oil from production wells to refineries or from refineries to consumers over thousands-of-kilometers-long distances. However, such large distances lead to a significant pressure drop in the pipeline system, which increases with flow velocity but decreases with pipe diameter and temperature. This pressure loss is mainly caused by high oil viscosity, drag $\&$ shear forces with pipe walls and blocking formed by wax crystallization, especially when transporting heavy crude oil (Wang et al., 2019; Koch et al., 2015).

Losses which are created by high oil viscosity, drag and friction between oil and pipeline walls are treated by adding drag reducing additives (surfactants, fibers and polymers) (Gudala et al., 2019). Other solutions include dilution and emulsification (oil-in-water and water-in-oil emulsion) as well as heated pipelines to reduce viscosity (Martínez-Palou et al., 2011; Bensakhria et al., 2004). For example, the Core Annular Flow system (CAF) greatly reduces flow viscosity, because adding a thin film of water near the internal pipe wall lubricates the internal oil core. However, this heat adds extra costs and thermal losses and may induce changes in the crude oil rheological properties which creates instability in the flow (Bensakhria et al., 2004). In addition to the pressure drop 
caused by frictional losses, there is also the variation in elevation due to the geographical nature of the pipeline route. Therefore, to maintain the oil flow and prevent critical pressure-drop values, many pressure-boosting stations should be installed along the pipeline route to raise the pumping pressure (Wang et al., 2019). The pumping power at each station can be supplied by a turbine, preferably a gas turbine, to drive a pump or compressor.

The advantage of using a Gas Turbine (GT) as a compressor or pump mover has been recognized very early due to its adjustable speed, low maintenance \& installation costs and the ability to use the transmitted product as fuel. Moreover, GT output capacity grows in cold weather, thus, compensating for the increase in the demand for heating power in winter (Sawyer, 1976). The GTs are very popular in electricity-generating power plants, cogeneration, turbojet engines, naval propulsion, O\&G transmission lines and large capacity district heating/cooling facilities (Chapman et al., 2016; Aklilu and Gilani, 2010; Al-Hamdan and Ebaid, 2006). Nevertheless, the poor GT part-load performance has led to utilizing different GT arrangements for further improvements, like controlled guide vanes, variable geometry turbines and multi-shaft designs (Poullikkas, 2005; Najjar and Abubaker, 2015; Mallinson and Lewis, 1948; Bălănescu and Homutescu, 2019; Najjar et al., 1993).

This study provides detailed modeling and analysis for a pressure-boosting station of a petroleum pipeline system using a two-shaft GT engine which operates on a heat-exchange cycle to drive a three-stage centrifugal pump. The variation in the GT parameters, such as compressor speed, compressor pressure ratio, turbine inlet temperature, specific fuel consumption, power output and efficiency, over a wide loading range was thoroughly investigated. This study can be summarized into three main steps: (1) Matching the GT engine components to optimize its performance and draw the "Power-Speed Curve", (2) matching the pipeline-system-requirements with the pump performance-map to generate the "Pump-Load Curve", (3) matching the GT "Power-Speed Curve" with the "PumpLoad Curve" to study the station overall performance. Also, a sensitivity analysis was carried out and the required calculations were implemented using Octave program.

\section{Plant Description}

To simplify the analysis and understand the working principles of the proposed pressure-boosting station, the system was divided into three parts: The two-shaft GT engine, the centrifugal pump and the pipeline. Figure 1 shows the components of the chosen GT engine connected to the centrifugal pump through a Gear Box (G.B). The two-shaft GT engine consists of two parts; the first is a Gas Engine (G.E), which comprises a compressor axially connected to a Compressor Turbine (CT) to provide the work required to drive the compressor. The second is a Power-Turbine (PT) connected to the load (G.B) on a separate shaft. This two-shaft design allows PT to rotate freely independent from the CT, thus enhancing the GT engine part-load efficiency compared with that of a single-shaft arrangement, especially for applications where the load requires a variable speed driver.

Air is sucked at point 1, compressed to high pressure (point 2) and preheated in the Heat exchanger (H.X) before it enters the Combustion Chamber (C.C) (point 6). It is then mixed with fuel under very high pressure. At this point, the combustion is initiated, producing very hot exhaust gases (point 3) that expand through the CT, providing the needed mechanical work to drive the compressor.

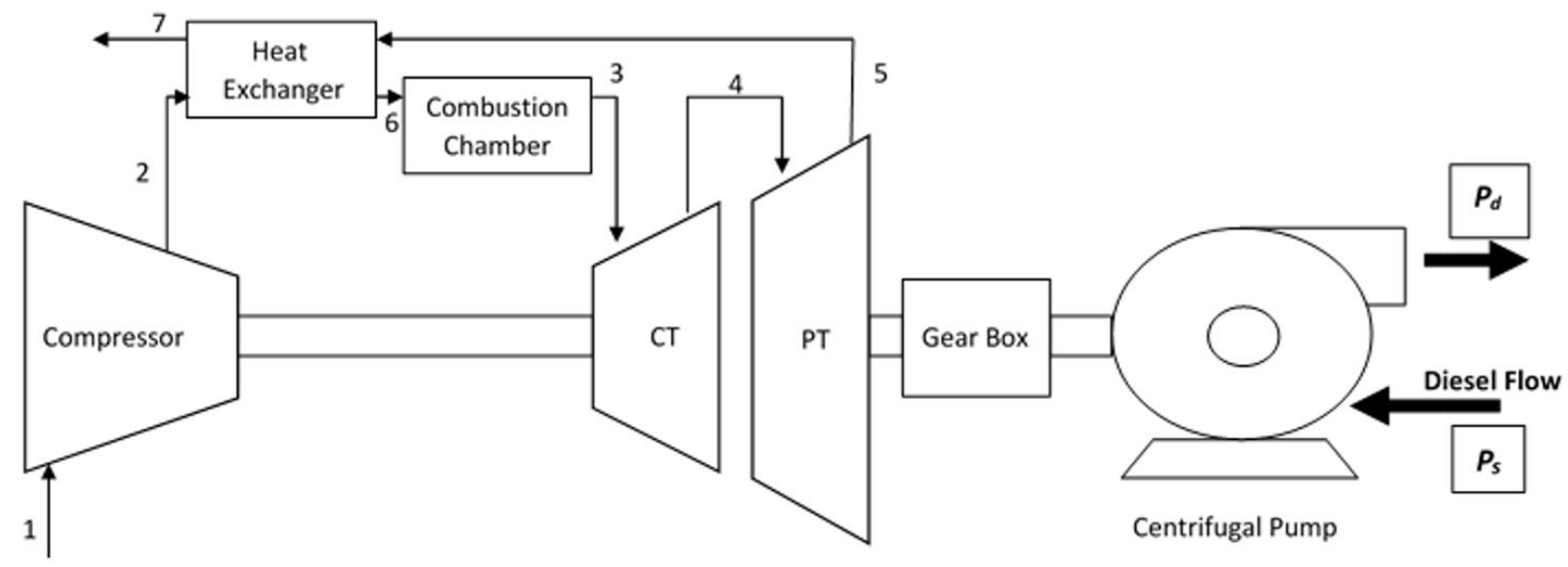

Fig. 1: A schematic diagram of the proposed pressure-boosting station driven by GT engine 
The exhaust gases coming out of CT (point 4) expand further in the PT to provide the mechanical work that drives the second shaft, which is connected to the load (G.B). Since pumps usually operate at lower rotational speeds than turbines, the G.B functions as speed reducer to make PT speed compatible with the pump speed. The pump converts the received mechanical input power into a hydraulic pumping power used to raise the pressure of the oil inside the pipeline to compensate for the pressure drop and maintains the flow.

\section{Methodology and Mathematical Modeling}

In this section, the mathematical modeling of the petroleum pressure-boosting station is presented. The mathematical model includes the thermodynamic and fluid mechanics analyses of the two-shaft GT engine, centrifugal pump and the pipeline system are discussed. In addition, the matching process of all components of the proposed pressure-boosting station is described in this section. The brief flowchart shown in Fig. 2 shows the steps sequence which was used during work.

\section{GT Engine Thermodynamic Analysis}

The GT engine is thermodynamically modelled using equations given in (Cohen et al., 1987) and performance maps retrieved from (Turbocompressor, 2016) for the compressor and from (Smooth Turbine Maps, 2018) for the CT and PT. Scaling techniques provided by (Chapman et al., 2016; Gilani et al., 2008) were used to match the CT and PT performance maps with the GT design-point.

\section{a) Compressor}

The rise in air temperature and the work required during the compression process are given by Eq. (1) and Eq. (2), respectively.

$$
\begin{aligned}
& \Delta T_{12}=\frac{T_{1}}{\eta_{c}} \times\left(r_{c}^{\frac{k_{a}-1}{k_{a}}}-1\right) \\
& W_{c}=m \times C_{p, a} \times \Delta \mathrm{T}_{12}
\end{aligned}
$$

\section{b) Heat Exchanger (H.X)}

The rise in temperature of the cold fluid stream, decrease in temperature of the hot fluid stream and the pressure drop across the H.X are given by Eq. (3), Eq. (4) and Eq. (5), respectively.

$$
\begin{aligned}
& T_{6}-T_{2}=\epsilon \times\left(T_{5}-T_{2}\right) \\
& T_{5}-T_{7}=\epsilon \times \frac{C_{p, a}}{C_{p, g}} \times\left(T_{5}-T_{2}\right)
\end{aligned}
$$

$$
\begin{aligned}
& \Delta P_{h a}=P_{2} \times \frac{\Delta P_{h a}}{P_{2}}(\text { air side }) \\
& \Delta P_{h g}=0.01 \text { Bar }(\text { gas side })
\end{aligned}
$$

\section{c) Combustion Chamber (C.C)}

By applying mass and energy balance across the C.C, the fuel-air-ratio $(f)$ is calculated using Eq. (6) and the pressure drop across C.C is calculated using Eq. (7):

$$
\begin{aligned}
& f=\frac{C_{p, g} \times\left(T_{3}-298\right)+C_{p, a} \times\left(298-T_{6}\right)}{C_{p, g} \times\left(T_{3}-298\right)+H . \mathrm{V} .} \\
& \Delta P_{c c}=P_{6} \times \frac{\Delta P_{c c}}{P_{6}}
\end{aligned}
$$

\section{d) Compressor Turbine (CT)}

The temperature drop across the CT depends on turbine's efficiency $\left(\eta_{c t}\right)$ and pressure ratio $\left(r_{c t}\right)$ and is calculated using Eq. (8). The CT outlet temperature is calculated by Eq. (9) while the extracted work is calculated using Eq. (10):

$\Delta T_{34}=T_{3} \times \eta_{c t} \times\left(1-\left(\frac{1}{r_{c t}}\right)^{\frac{k_{g}-1}{k_{g}}}\right)$

$T_{4}=T_{3} *\left(1-\Delta T_{34} / T_{3}\right)$

$W_{c t}=W_{c}=m * \mathrm{C}_{\mathrm{p}, \mathrm{g}} * \Delta T_{34}$

\section{e) Power Turbine (PT)}

The temperature drop across the PT can be expressed by Eq. (11) while the turbine outlet temperature and the extracted work are calculated using Eq. (12) and Eq. (13), respectively.

$$
\begin{aligned}
& \Delta T_{45}=T_{4} \times \eta_{p t} \times\left(1-\left(\frac{1}{r_{p t}}\right)^{\frac{k_{g}-1}{k_{g}}}\right) \\
& \mathrm{T}_{5}=\mathrm{T}_{4} \times\left(1-\Delta \mathrm{T}_{45} / \mathrm{T}_{4}\right) \\
& W_{p t}=m \times C_{p, g} \times \Delta T_{45}
\end{aligned}
$$




\section{Matching GT Engine Components}

The compressor and CT were matched based on three compatibility conditions: Work, rotational speed and mass flow rate. These conditions are expressed by Eq. (14), Eq. (15) and Eq. (16). The CT and PT are not mechanically connected, therefore only the mass flow compatibility condition given by Eq. (17) should be satisfied. The pressure ratios across each component, considering pressure losses across H. X and C.C, are related by Eq. (18). Equation (19) is used to calculate the power output of the GT engine:

$$
\begin{aligned}
& \frac{\Delta T_{34}}{T_{3}}=\frac{\Delta T_{12}}{T_{1}} * \frac{T_{1}}{T_{3}} * \frac{C_{p, a}}{C_{p, g} * \eta_{m}} \\
& \frac{N_{c}}{\sqrt{T_{1}}}=\frac{N_{c t}}{\sqrt{T_{3}}} \sqrt{\frac{T_{3}}{T_{1}}} \\
& \frac{m \sqrt{T_{3}}}{P_{3}}=\frac{\mathrm{m} \sqrt{T_{1}}}{P_{1}} * \frac{P_{1}}{P_{2}} * \sqrt{\frac{T_{3}}{T_{1}}} \\
& \frac{\mathrm{m} \sqrt{T_{4}}}{P_{4}}=\frac{\mathrm{m} \sqrt{T_{3}}}{P_{3}} * \frac{P_{3}}{P_{4}} * \sqrt{\frac{T_{4}}{T_{3}}} \\
& \frac{P_{2}}{P_{1}}=\frac{P_{2}}{P_{6}} * \frac{P_{6}}{P_{3}} * \frac{P_{3}}{P_{4}} * \frac{P_{4}}{P_{5}} * \frac{P_{5}}{P_{7}}
\end{aligned}
$$

$W_{g t}=W_{p t}=\dot{m}=C_{p, g} \times T_{4} \times \mu_{p t} \times\left(1-\left(\frac{1}{r_{p t}}\right)^{\frac{k g-1}{k g}}\right)$

Figure 3 was produced using Eq. (19) to plot the change in GT engine power output as a function of the PT speed $\left(N_{p t}\right)$ at different $N_{c}$ values. The Specific Fuel Consumption (SFC) as well as the GT engine thermal efficiency $\left(\eta_{G T, t h}\right)$ are expressed by Eq. (20) and Eq. (21), respectively:

$S F C=\frac{3600 \times f \times \dot{m}}{W_{n e t}}$

$\eta_{G T, t h}=\frac{3600}{S F C \times H . V}$

\section{Matching the Centrifugal Pump and the Pipeline System}

Matching the pump performance with the pipeline system requirements is presented in this subsection. Figure 4 shows two subsequent pressure-boosting stations (hypothetical) and illustrates the elevation difference between them, which is postulated by the nature of terrain characteristics.

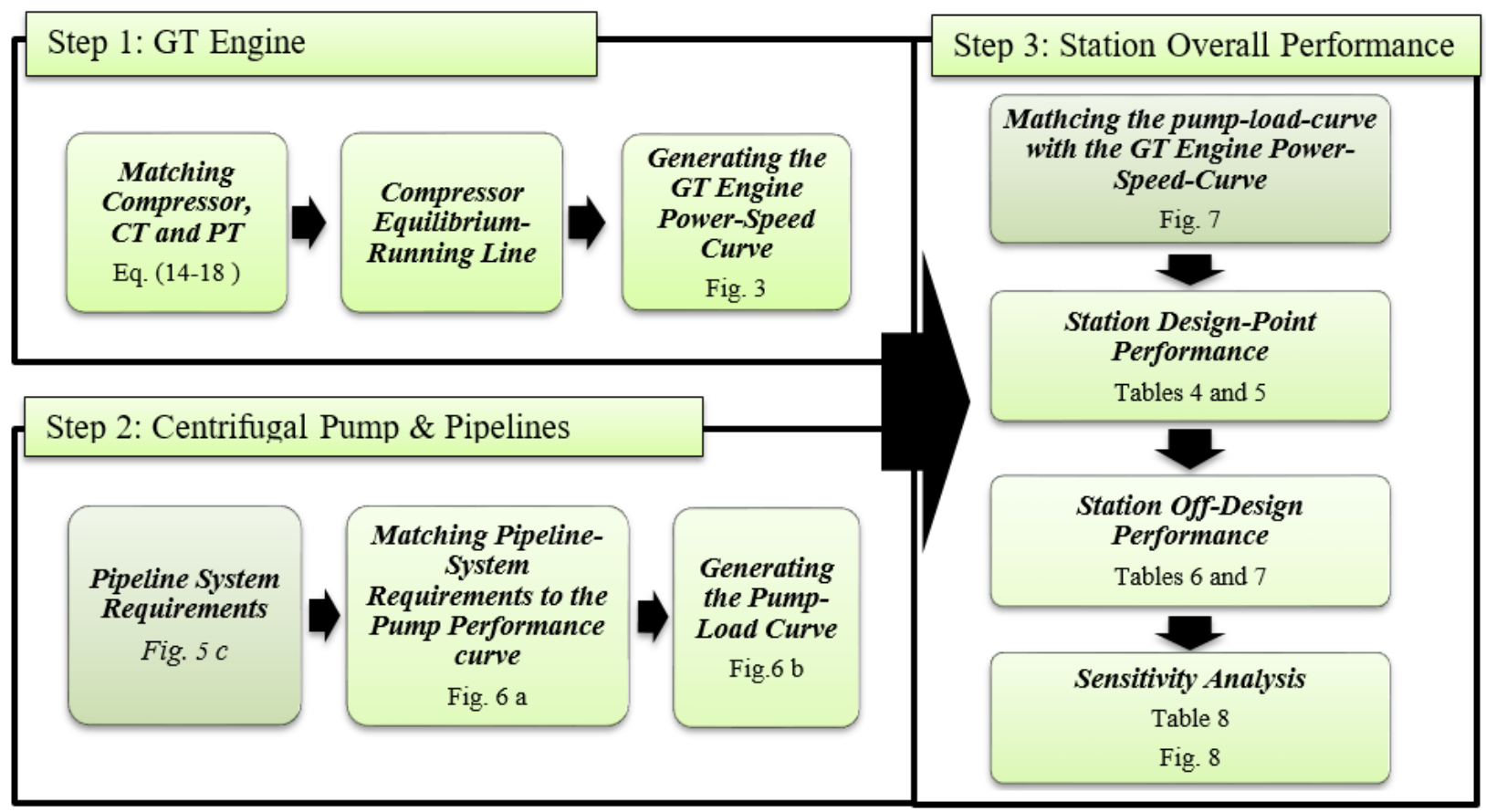

Fig. 2: Flowchart diagram summarizing the major steps of the modeling process 


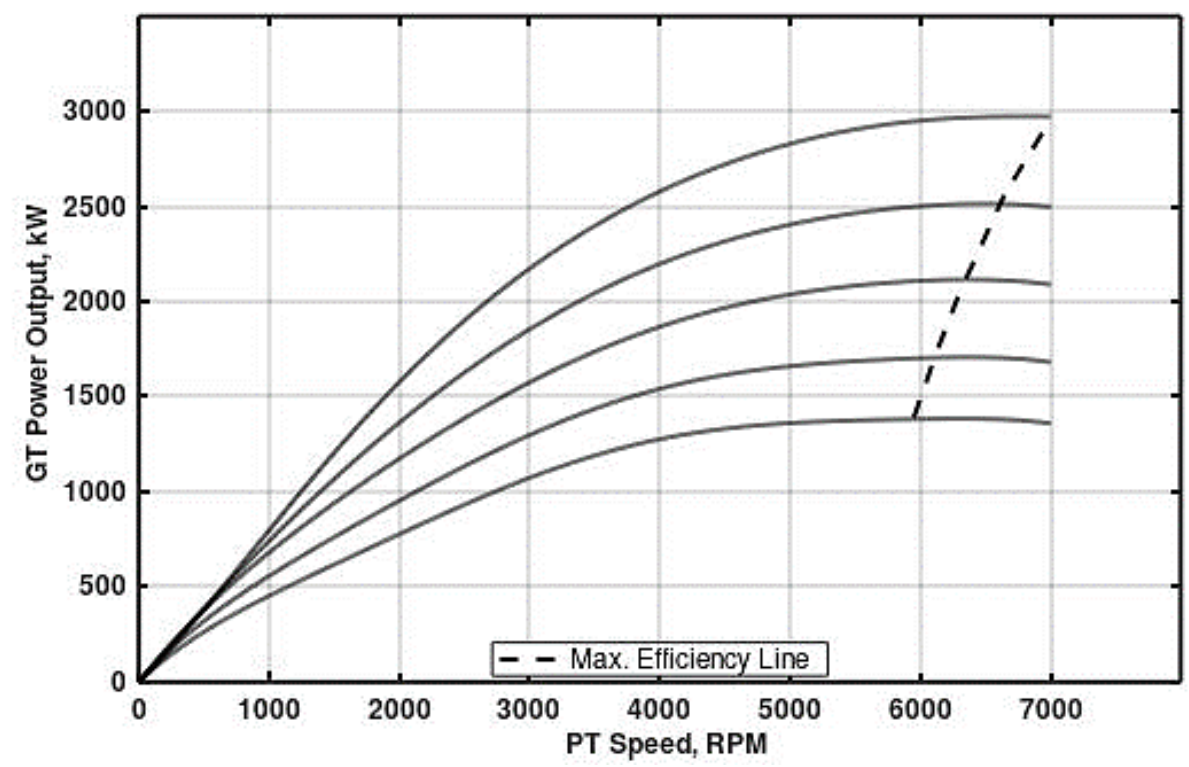

Fig. 3: GT engine power-speed curve at typical different Nc values.

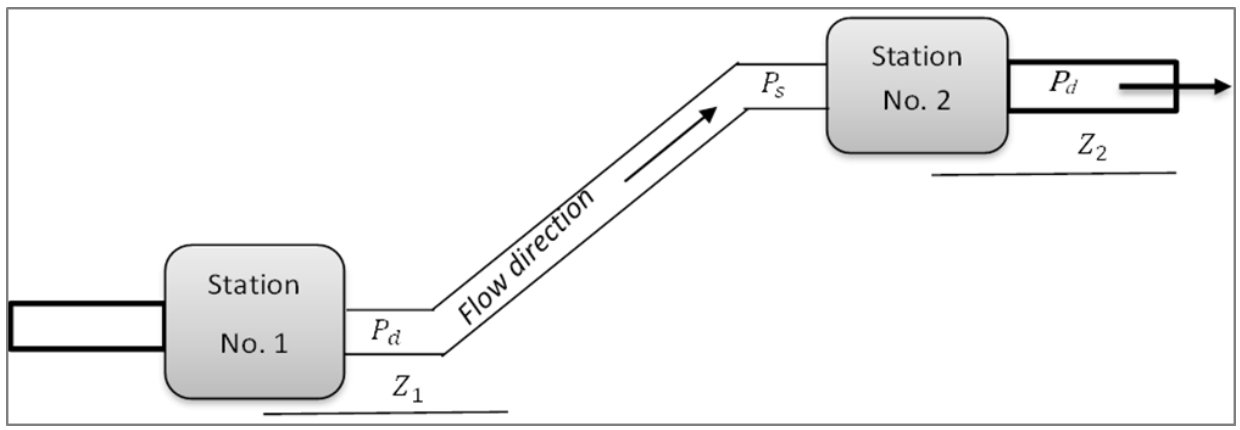

Fig. 4: Schematic diagram showing two hypothetical pressure-boosting stations on the same pipeline

The energy equation, Eq. (22), is applied between the discharge port of station 1 and the suction port of station 2 (Fox et al., 2012). When the liquid flows, the pressure drop $\left(\Delta P_{i}\right)$ is calculated using Eq. 23. The fluid velocity $(V)$ is a function of the flow rate $(\mathrm{Q})$ as described in Eq. (24). Equation (25) is used to generate the pipeline-system differential-head curve $(\Delta P / \gamma)$, shown in Fig. 5:

$\Delta P=\left(z_{2}-z_{1}\right) \times \gamma+\Delta P_{1}$

$\Delta P_{1}=0.0239 * \frac{\rho * \beta * L * V^{2}}{g * D}$

where, $V=\frac{4 Q}{\pi D^{2}}$

$\Delta P_{1}=0.0239 * \frac{16}{\pi^{2}} * \frac{\rho * \beta * L * Q^{2}}{g * D^{5}}$

$\Delta P \gamma\left(z_{2}-z_{1}\right)+0.0239 * \frac{16}{\pi^{2}} * \frac{\rho * \beta * L * Q^{2}}{g * D^{5}}$
The three-stage centrifugal pump provides the differential head $(\Delta \mathrm{P} / \gamma)$ required to compensate for the elevation head $(\Delta \mathrm{z})$ and head loss $(\Delta \mathrm{Pi} / \gamma)$ along the length of the pipeline. The pressure rise $(\Delta \mathrm{P})$, pump output power and pump efficiency are expressed by Eq. (26, 27 and 28), respectively (Fox et al., 2012):

$\Delta P=P_{d}-P_{s}$

$W_{p, \text { out }}=Q * \Delta P$

$\eta_{p}=W_{p, \text { out }} / W_{p, \text { in }}$

The pipeline differential-head $(\Delta P / \gamma)$ is matched with the pump-performance curve, as shown in Fig. 6a and the results of matching are used to generate the pump-load curve shown in Fig. 6b.

$W_{p, i n}=\Delta P \times Q$ 
In a typical petroleum pipeline, the required pump discharge pressure is about $5900 \mathrm{KPa}$ and the minimum suction pressure is about $500 \mathrm{KPa}$ (Sawyer, 1976).

\section{Matching the GT Power-Speed Curve with the Pump Load Curve}

In this section, the GT power-speed curve (Fig. 3) and the pump load curve (Fig. 6b) are matched, and the result is shown in Fig. 7. The power input into the pump is related to the GT power output by Eq. (30), where $\left(\eta_{m}\right)$ is the geartrain mechanical efficiency. The gearbox is chosen so that the design point on the pump-load curve is located on the GT engine maximum-efficiency-line. This condition is satisfied by applying Eq. (31), where $R_{o p t}$ is the optimum gearbox reduction ratio required to assure that the GT engine operates at maximum efficiency. Finally, the overall efficiency of the entire pressureboosting plant $\left(\eta_{o}\right)$ is expressed by Eq. (32):

$$
W_{p, \text { in }}=W_{g t, o u t} \times \eta_{m}
$$

$R_{o p t}=\frac{\left(\omega_{p t}\right)_{\max . e f f i c i e n c y}}{\left(\omega_{p}\right)_{d p}}$

$\eta_{o}=\eta_{g t} * \eta_{m} * \eta_{p}$
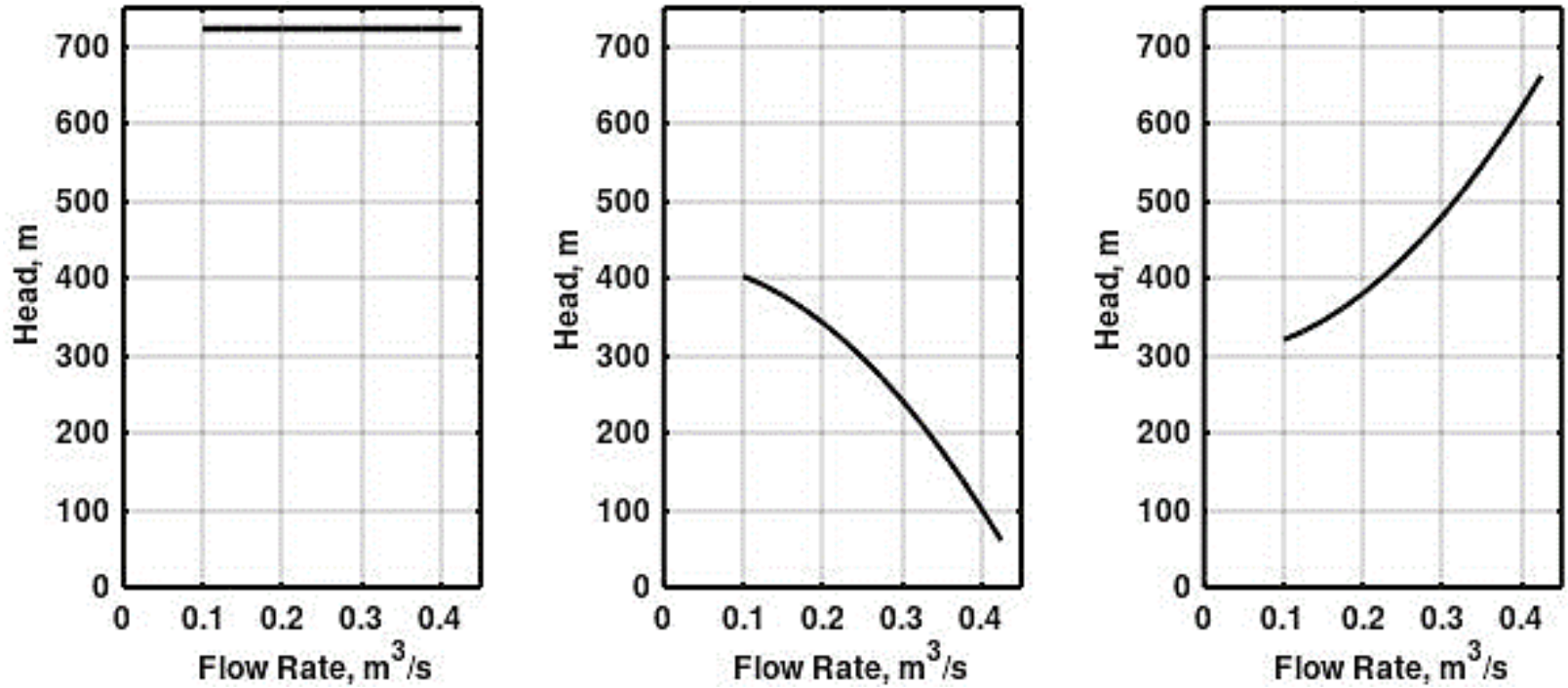

Fig. 5: Typical pipeline system head-flow curves: (a) discharge head, (b) suction head, (c) differential head
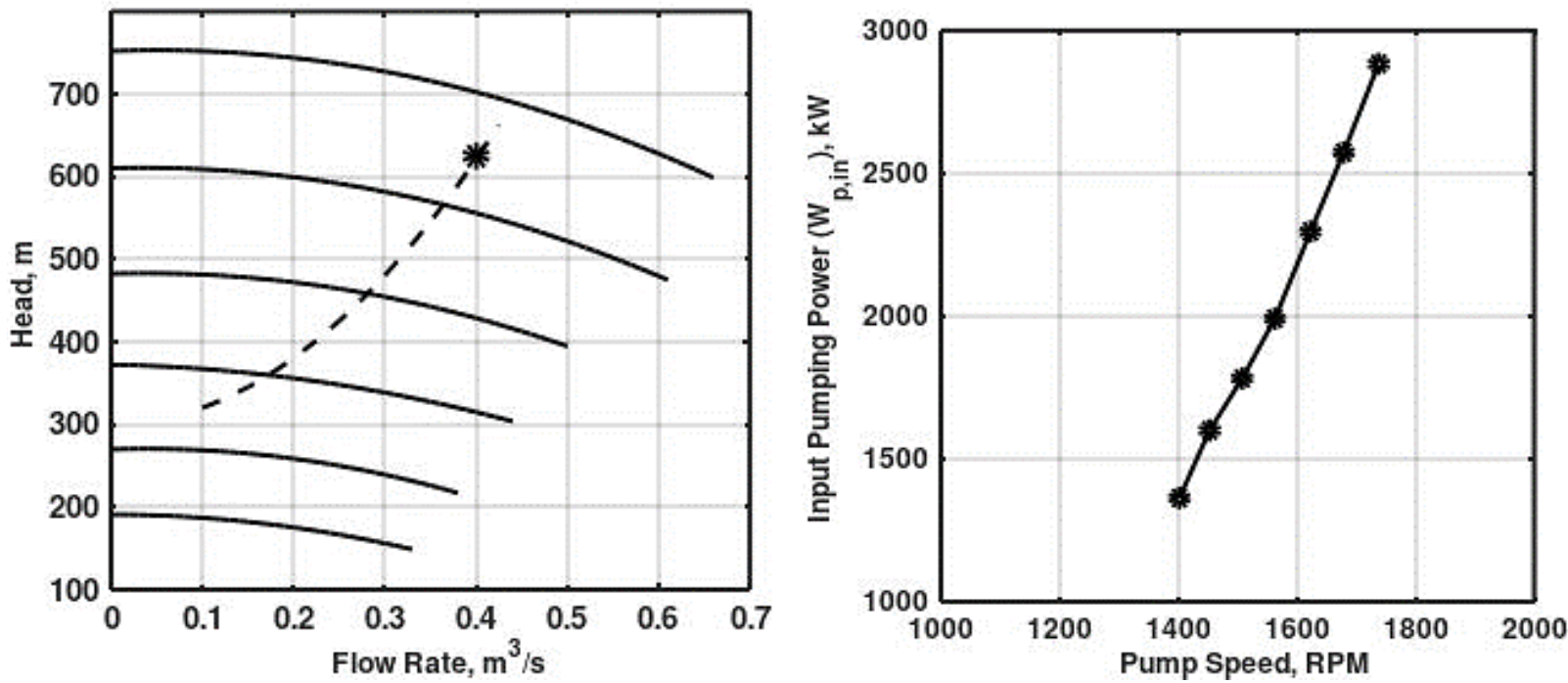

Fig. 6: (a) Pipeline-system differential-head curve matched to the pump-performance curve, (b) the pump load curve 


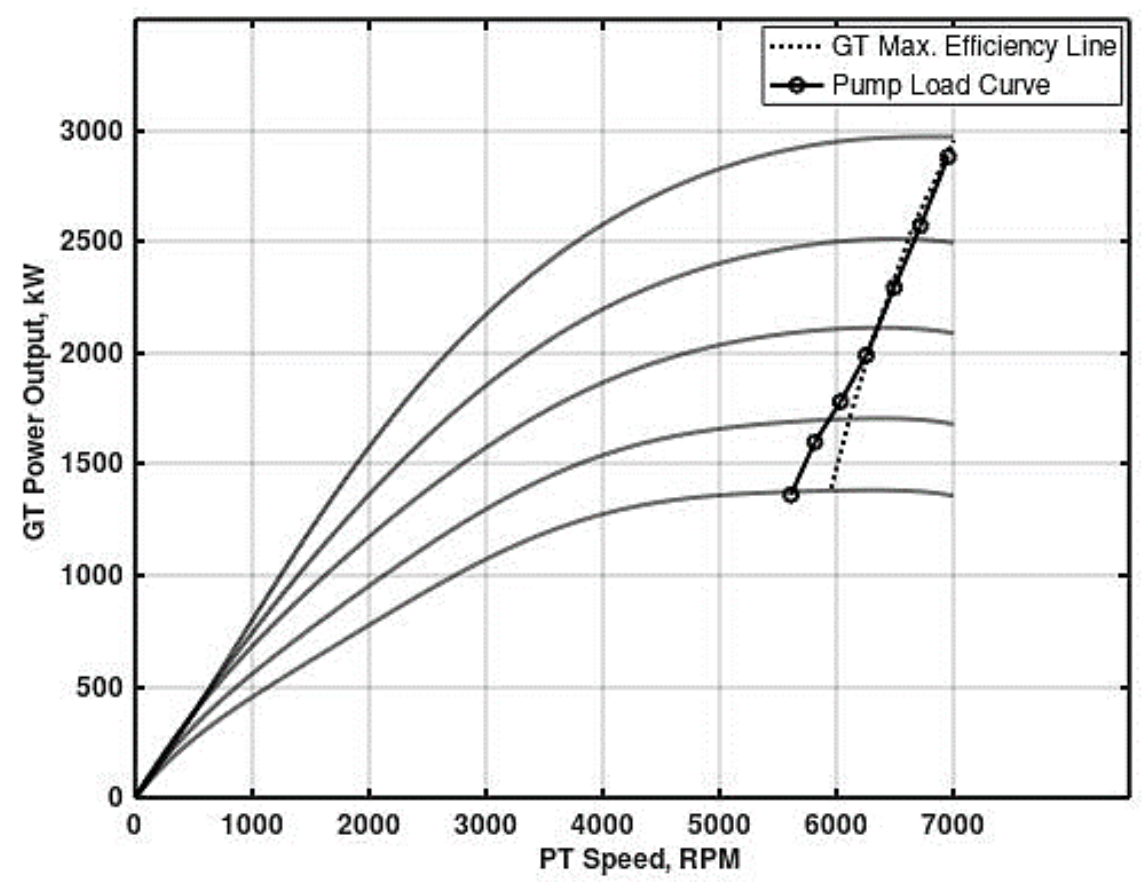

Fig. 7: Matching the pump load curve with the GT engine power-speed

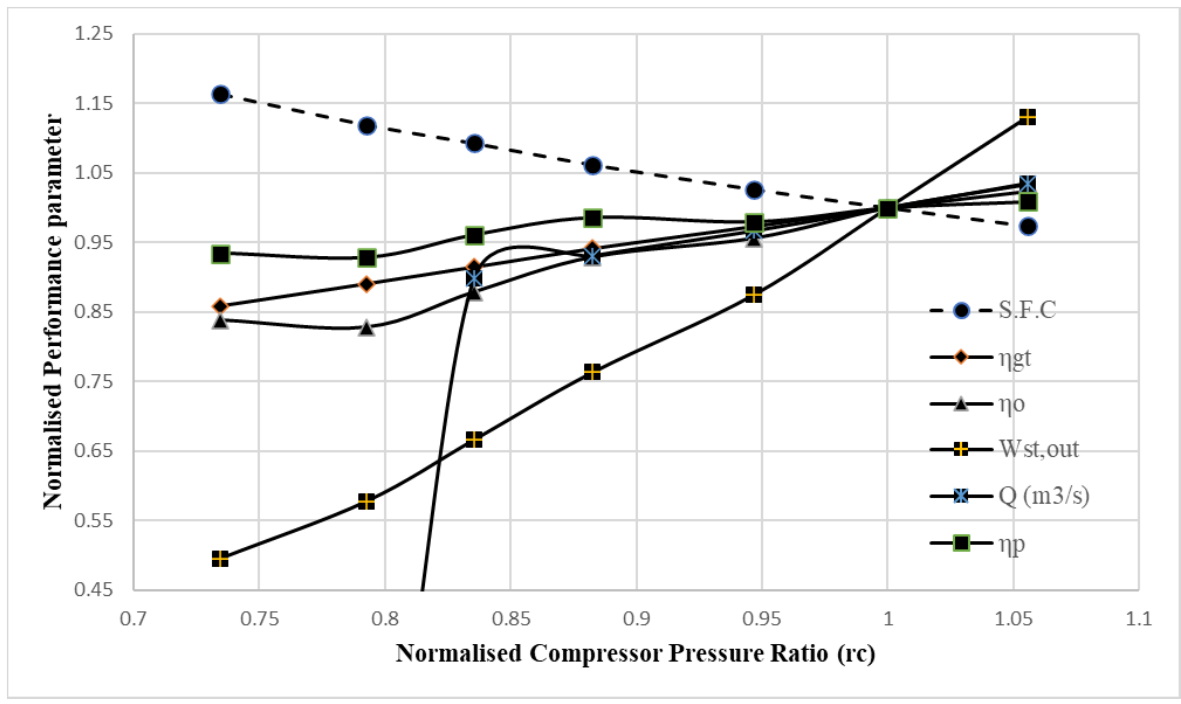

Fig. 8: The normalized effect of compressor pressure ratio $\left(r_{c}\right)$ on the station performance parameters

\section{Results and Discussion}

\section{Design Point Calculations}

Table 2 shows the station performance parameters while Table 1 shows the properties, assumptions and operating conditions of the proposed pressure-boosting station at design point. It can be seen from Fig. 7 that the pump matches the GT engine near its maximum-efficiency-line over a wide loading range, which emphasizes the significance of employing the two-shaft GT design in variable speed applications. In fact, when the station runs near the GT maximum-efficiency line, the plant part-load efficiency is at its optimum value, thus the two-shaft GT engine is a very suitable prime mover for centrifugal pumps and compressors in many applications.

\section{Off-Design Calculations}

The station off-design behavior was investigated over the loading range specified along the pump load curve illustrated on Fig. 6b. It is clear from Fig. 7 that at higher 
compressor pressure ratios $\left(r_{c}\right)$, the pump-load-curve is perfectly matched with the GT engine maximumefficiency-line. Table 3 shows the station off-design properties while Table 4 shows the station off-design performance parameters.

Non-dimensional analysis was carried out to study the effect of changing the compressor pressure ratio $\left(r_{c}\right)$ on the plant performance parameters, mainly the GT engine efficiency $\left(\eta_{g t}\right)$, the pump efficiency $\left(\eta_{p}\right)$, the overall power output $\left(W_{s t, o u}\right)$ and the overall efficiency $\left(\eta_{o v}\right)$. Figure 8 shows that as $r_{c}$ increases, GT efficiency rises, and the station power output also increases at higher compression ratios. The station performance is enhanced at higher $r_{c}$ values, since as the compression ration increases, the TIT increases. It is worth noting that references (Cohen et al., 1987; Najjar and Ismail, 1990) studied the effects of TIT and compression ratios $\left(r_{c}\right)$ on the performance of a heat-exchange cycle, independently. They concluded that the efficiency increases with $r_{c}$ and the power output increases significantly with TIT. Thus, increasing both $r_{c}$ and TIT leads to higher GT engine efficiency and power output, as confirmed by the results indicated in Table 4 and Fig. 7. This result agrees with the conclusions in references (Cohen et al., 1987; Najjar and Ismail, 1990). Figure 8 also shows an increase in the pump efficiency with $r_{c}$, which is a logical result as the operation of the system moves from the low to the high efficiency region (points 1 to 7 on Fig. 6b) at higher loading conditions. This mainly relies on the nature of the pump performance-curve and pipeline differentialhead-curve. Besides, the station overall efficiency $\left(\eta_{o}\right)$ also increases with $r_{c}$ since it is proportional to the efficiencies of both the pump $\left(\eta_{p}\right)$ and the GT engine $\left(\eta_{g t}\right)$ according to Eq. (25).

\section{Sensitivity Analysis}

To quantify the effect of varying the compressor pressure ratio $\left(r_{c}\right)$ on the performance parameters of the pressure-boosting station, a sensitivity analysis was performed. Table 5 summarizes the change in each performance parameter for every $10 \%$ drop in $r_{c}$ from its value at design-point.

Table 1: The properties and operating conditions of the oil-pipelines-pressure-boosting station, at design point

\begin{tabular}{|c|c|c|}
\hline & Operating condition & Value \\
\hline \multirow[t]{20}{*}{ GT Engine Cohen et al. (1987) } & Compressor Pressure Ratio, $r_{c}$ & 8.44 \\
\hline & Compressor Rotational Speed, $N_{c}$ & $97.95 \%$ \\
\hline & Compressor Isentropic. Efficiency, $\eta_{c}$ & $79 \%$ \\
\hline & Air Mass Flow Rate, & $10.04 \mathrm{~kg} / \mathrm{s}$ \\
\hline & CT Pressure Ratio, $r_{c t}$ & 2.77 \\
\hline & CT Isentropic Efficiency, $\eta_{c t}$ & $85 \%$ \\
\hline & CT Inlet Temperature, $T_{3}$ & $1411 \mathrm{~K}$ \\
\hline & PT Pressure Ratio, $r_{p t}$ & 3.06 \\
\hline & PT Rotational Speed, $N_{p t}$ & $6716 \mathrm{rpm}$ \\
\hline & PT Isentropic Efficiency, $\eta_{p t}$ & 0.850 \\
\hline & PT Inlet Temperature, $T_{4}$ & $\mathrm{~K}$ \\
\hline & CT Inlet Temperature, $T_{3}$ & $1411 \mathrm{~K}$ \\
\hline & Ambient Pressure, $p_{a}=p_{1}$ & 1 bar \\
\hline & Ambient Temperature $T_{\mathrm{a}}=T_{1}$ & $288 \mathrm{~K}$ \\
\hline & Shaft Mechanical Efficiency, $\eta_{m}$ & 0.99 \\
\hline & Combustion Efficiency, $\eta_{b}$ & 0.99 \\
\hline & Pressure Drop across the Combustion Chamber, $\Delta p_{c c} / p_{6}$ & $0.03 * \mathrm{P}_{\mathrm{d}}$ \\
\hline & H.X Effectiveness, $\epsilon$ & 0.85 \\
\hline & Pressure Drop across the H.X (air-side), $\Delta p_{h a} / \mathrm{p}_{2}$ & $0.02 * \mathrm{P}_{\mathrm{d}}$ \\
\hline & Pressure Drop across the H.X (gas-side), $\Delta p_{h g}$ & 0.01 bar \\
\hline \multirow[t]{10}{*}{ Pump and Pipelines (Sawyer, 1976; Gilani et al., 2008) } & Pump Head, $\mathrm{H}$ & $625 \mathrm{~m}$ \\
\hline & Pump Rotational Speed, $N_{p}$ & $1679 \mathrm{rpm}$ \\
\hline & Volume Flow Rate, $Q_{d}$ & $0.400 \mathrm{~m}^{3} / \mathrm{s}$ \\
\hline & Suction Pressure, $P_{s}$ & $800 \mathrm{kPa}$ \\
\hline & Minimum Suction Pressure, $\mathrm{p}_{\mathrm{s}, \min }$ & $500 \mathrm{kPa}$ \\
\hline & Delivery (Discharge) Pressure, $p_{d}$ & $5900 \mathrm{kPa}$ \\
\hline & Pipeline Length, L & $1000 \mathrm{~km}$ \\
\hline & Pipeline Diameter, D & $0.381 \mathrm{~m}$ \\
\hline & Pipe Friction Factor, $\beta$ & 0.04 \\
\hline & Elevation Difference, $z_{2}-z_{1}$ & $300 \mathrm{~m}$ \\
\hline Oil Liquid Properties (Diesel) Liquids - & Avg. Specific Weight, $\gamma$ & $8162 \mathrm{~N} / \mathrm{m}^{3}$ \\
\hline \multirow[t]{3}{*}{ Kinematic Viscosities (2018) } & Avg. Density, $\rho$ & $832 \mathrm{~kg} / \mathrm{m}^{3}$ \\
\hline & Avg. Dynamic Viscosity, $\mu$ & 0.0248 Pa.s \\
\hline & Heating Value, H.V & $42517 \mathrm{~kJ} / \mathrm{kg}$ \\
\hline
\end{tabular}


Table 2: The performance parameters of the oil-pipelines-pressure-boosting station, at design point

\begin{tabular}{lll}
\hline GT Engine & GT Power Output, $W_{g t, o u t}$ & $2599 \mathrm{~kW}$ \\
& GT Efficiency, $\eta_{g t}$ & $37.5 \%$ \\
& & $0.217 \mathrm{~kg} / \mathrm{kWh}$ \\
Pump & Specific Fuel Consumption, SFC & $2573 \mathrm{~kW}$ \\
& Pump power input, $W_{p}$ & $79.3 \%$ \\
Overall Station & Station power output, $W_{o v}$ & $2040 \mathrm{~kW}$ \\
& Station efficiency, $\eta_{o v}$ & $29.7 \%$ \\
\hline
\end{tabular}

Table 3: The station off-design properties at different $r_{c}$ values corresponding to the points along the pump-load-curve shown in Fig. $6 \mathrm{~b}$

\begin{tabular}{|c|c|c|c|c|c|c|c|c|c|c|c|c|}
\hline & \multicolumn{9}{|c|}{ GT Engine } & \multirow{2}{*}{\multicolumn{3}{|c|}{ Pump }} \\
\hline & \multicolumn{4}{|c|}{ Compressor } & \multicolumn{2}{|l|}{$\mathrm{CT}$} & \multicolumn{3}{|l|}{$\mathrm{PT}$} & & & \\
\hline & $\#$ & $r_{c}$ & $\mathrm{~N}_{\mathrm{c}}(\%)$ & $\dot{m}_{a i r}(\mathrm{~kg} / \mathrm{s})$ & $r_{c t}$ & TIT (K) & $N_{p t}(\mathrm{rpm})$ & $\mathrm{r}_{\mathrm{pt}}$ & $\eta p t(\%)$ & $N_{p}(\mathrm{rpm})$ & $\mathrm{H}(\mathrm{m})$ & $\mathrm{Q}\left(\mathrm{m}^{3} / \mathrm{s}\right)$ \\
\hline Part Load & 1 & 6.20 & 90.05 & 8.12 & 2.63 & 1190 & 5608 & 2.22 & 84.7 & 1402 & 450 & 0.275 \\
\hline & 2 & 6.69 & 91.78 & 8.54 & 2.67 & 1238 & 5812 & 2.35 & 84.7 & 1453 & 481 & 0.300 \\
\hline & 3 & 7.05 & 93.05 & 8.85 & 2.70 & 1274 & 6032 & 2.46 & 84.9 & 0.325 & 512 & 1508 \\
\hline & 4 & 7.45 & 94.44 & 9.18 & 2.72 & 1313 & 6252 & 2.57 & 85.0 & 0.350 & 545 & 1563 \\
\hline & 5 & 7.99 & 96.35 & 9.65 & 2.75 & 1367 & 6492 & 2.74 & 85.0 & 0.375 & 583 & 1623 \\
\hline Design Point & 6 & 8.44 & 97.95 & 10.04 & 2.76 & 1411 & 6716 & 2.88 & 85.0 & 0.400 & 625 & 1679 \\
\hline Overload & 7 & 8.91 & 99.61 & 10.44 & 2.78 & 1458 & 6952 & 3.03 & 85.0 & 0.425 & 665 & 1738 \\
\hline
\end{tabular}

Table 4: The station off-design performance at different $r_{c}$ values corresponding to the points along the pump-load-curve shown in Fig. $6 \mathrm{~b}$

\begin{tabular}{|c|c|c|c|c|c|c|c|c|c|}
\hline & \multirow[b]{2}{*}{ \# } & \multirow[b]{2}{*}{$r_{c}$} & \multicolumn{2}{|l|}{ GT Engine } & \multicolumn{2}{|l|}{ Pump } & \multicolumn{3}{|c|}{ Overall Performance } \\
\hline & & & $W_{g t, \text { out }}(\mathrm{kW})$ & $S F C(\mathrm{~kg} / \mathrm{kWh})$ & $(\%)$ & $(\mathrm{kW})$ & $(\%)$ & $(k W)$ & $(\%)$ \\
\hline \multirow[t]{5}{*}{ Part Load } & 1 & 6.20 & 1377 & 0.263 & 32.2 & 1363 & 74.1 & 1010 & 24.9 \\
\hline & 2 & 6.69 & 1616 & 0.253 & 33.4 & 1600 & 73.6 & 1178 & 24.6 \\
\hline & 3 & 7.05 & 1800 & 0.247 & 34.3 & 1782 & 76.2 & 1358 & 26.1 \\
\hline & 4 & 7.45 & 2011 & 0.240 & 35.3 & 1991 & 78.2 & 1557 & 27.6 \\
\hline & 5 & 7.99 & 2320 & 0.232 & 36.5 & 2296 & 77.7 & 1784 & 28.4 \\
\hline Design Point & 6 & 8.44 & 2600 & 0.226 & 37.5 & 2573 & 79.3 & 2040 & 29.7 \\
\hline Overload & 7 & 8.91 & 2913 & 0.220 & 38.4 & 2883 & 80.0 & 2307 & 30.7 \\
\hline
\end{tabular}

Table 5: The amount of change in performance parameters for every $10 \%$ drop in compressor pressure ratio $\left(r_{c}\right)$

\begin{tabular}{llllll}
\hline$\left(r_{c}\right)$ & $Q$ & $W_{s t}$ & $\eta_{g t}$ & $\eta_{p}$ & $\eta_{o}$ \\
\hline$-10 \%$ & $-11 \%$ & $-21 \%$ & $-5 \%$ & $-1.5 \%$ & $-6.5 \%$
\end{tabular}

\section{Conclusion}

- The GT engine components were optimally matched to generate the GT engine maximum-efficiency-line

- The pump performance was matched with the pipelinesystem requirements to generate the pump load-curve

- The pump load-curve was matched to the GT engine power-speed-curve along its maximum-efficiency-line

- The station net power output and specific fuel consumption were $2 \mathrm{MW}$ and $0.217 \mathrm{~kg} / \mathrm{kWh}$, respectively

- Efficiencies of the GT engine, pump and the entire station at D.P were $37.5,79.3$ and $29.7 \%$, respectively

- At $50 \%$ power-output loading from D.P, the GT engine part-load efficiency was $32.2 \%$ (Table 4 )

- At $50 \%$ power-output loading from D.P, the pressure ratios of the compressor, CT and PT were reduced by
27, 4.7 and 26.7\%, respectively. Hence, the CT operating range is the most limited (Table 3 )

- For a $10 \%$ drop in $r_{c}$ from D.P, the station overall efficiency drops by only $6.5 \%$ (Table 5 )

\section{Acknowledgement}

This paper is devoted to the memory of Professor Yousef Najjar who passed away on the $7^{\text {th }}$ of March 2021.The authors would also like to thank the DAAD association for supporting and funding the study of the third author.

\section{Author's Contributions}

Yousef S. H. Najjar: Developed the concept and the research idea.

Mohammad Z. M. Yousef: Performed the modelling, simulation, obtained the results and wrote the initial draft. 
Aad M. A. Al-Mahgari: Wrote the final manuscript, revised and prepared it for publication.

\section{Ethics}

This research does not contain any studies involving human or animal participants performed by any of the authors.

This research paper is original and all authors have read and approved it and there are no ethical issues related.

\section{References}

Aklilu, B. T., \& Gilani, S. I. (2010). Mathematical modeling and simulation of a cogeneration plant. Applied Thermal Engineering, 30(16), 2545-2554. doi.org/10.1016/j.applthermaleng.2010.07.005

Akyurt, M., Lamfon, N. J., Najjar, Y. S. H., Habeebullah, M. H., \& Alp, T. Y. (1995). Modeling of waste heat recovery by looped waterin-steel heat pipes. International journal of heat and fluid flow, 16(4), 263-271. doi.org/10.1016/0142-727X(94)00023-6

Al-Hamdan, Q. Z., \& Ebaid, M. S. (2006). Modeling and simulation of a gas turbine engine for power generation. doi.org/10.1115/1.2061287

Barigozzi, G., Perdichizzi, A., Gritti, C., \& Guaiatelli, I. (2015). Techno-economic analysis of gas turbine inlet air cooling for combined cycle power plant for different climatic conditions. Applied Thermal Engineering, 82, 57-67. doi.org/10.1016/j.applthermaleng.2015.02.049

Bensakhria, A., Peysson, Y., \& Antonini, G. (2004). Experimental study of the pipeline lubrication for heavy oil transport. Oil \& gas science and technology, 59(5), 523-533. doi.org/10.2516/ogst:2004037.

Chapman, J. W., Lavelle, T. M., \& Litt, J. S. (2016). Practical techniques for modeling gas turbine engine performance. In 52nd AIAA/SAE/ASEE joint propulsion conference (p. 4527). doi.org/10.2514/6.2016-4527.

Cohen, H., Rogers, G. F. C., \& Saravanamutto, H. I. H. (1987). Gas Turbine Theory, Longman Scientific \& Technical.

Fox, R. W., McDonald, A. T., Pritchard, P. J. (2012). Fluid Mechanics. 8th ed. John Wiley \& Sons Inc.; 2012.

Gilani, S. I. U. H., Baheta, A. T., Majid, A., \& Amin, M. (2008). Thermodynamics approach to determine a gas turbine components design data and scaling method for performance map generation.

Gudala, M., Banerjee, S., Naiya, T. K., Mandal, A., Subbaiah, T., \& Rao, T. R. M. (2019). Hydrodynamics and energy analysis of heavy crude oil transportation through horizontal pipelines using novel surfactant. Journal of Petroleum Science and Engineering, 178, 140-151. doi.org/10.1016/j.petrol.2019.03.027.
Guo, Y., Meng, X., Wang, D., Meng, T., Liu, S., \& He, R. (2016). Comprehensive risk evaluation of longdistance oil and gas transportation pipelines using a fuzzy Petri net model. Journal of Natural Gas Science and Engineering, 33, 18-29. doi.org/10.1016/j.jngse.2016.04.052.

Hart, A. (2014). A review of technologies for transporting heavy crude oil and bitumen via pipelines. Journal of Petroleum Exploration and Production Technology, 4(3), 327-336. doi.org/10.1007/s13202-013-0086-6.

Bălănescu, D. T., \& Homutescu, V. M. (2019). Performance analysis of a gas turbine combined cycle power plant with waste heat recovery in Organic Rankine Cycle. Procedia Manufacturing, 32, 520-528. doi.org/10.1016/j.promfg.2019.02.248

Koch, G., Ayello, F., Khare, V., Sridhar, N., \& Moosavi, A. (2015). Corrosion threat assessment of crude oil flow lines using Bayesian network model. Corrosion Engineering, Science and Technology, 50(3), 236-247. doi.org/10.1179/1743278215Y.0000000005.

Liquids - Kinematic Viscosities. (2018). Engineering Toolbox [was available on. http://www.engineeringtoolbox.com

Mallinson, D. H., \& Lewis, W. G. E. (1948). The partload performance of various gas-turbine engine schemes. Proceedings of the Institution of Mechanical Engineers, 159(1), 198-219. doi.org/10.1243/PIME_PROC_1948_159_019_02

Martínez-Palou, R., de Lourdes Mosqueira, M., ZapataRendón, B., Mar-Juárez, E., Bernal-Huicochea, C., de la Cruz Clavel-López, J., \& Aburto, J. (2011). Transportation of heavy and extra-heavy crude oil by pipeline: A review. Journal of petroleum science and engineering, 75(3-4), 274-282. doi.org/10.1016/j.petrol.2010.11.020

Najjar, Y. S. H., \& Ismail, M. S. (1990). Optimum pressure ratios for different gas turbine cycles. High Temperature Technology, 8(4), 283-289. doi.org/10.1080/02619180.1990.11753494.

Najjar, Y. S. H., Akyurt, M., Al-Rabghi, O. M., \& Alp, T. (1993). Cogeneration with gas turbine engines. Heat Recovery Systems and CHP, 13(5), 471-480. doi.org/10.1016/0890-4332(93)90048-Z.

Najjar, Y. S., \& Abubaker, A. M. (2015). Indirect evaporative combined inlet air cooling with gas turbines for green power technology. International journal of refrigeration, 59, 235-250. doi.org/10.1016/j.ijrefrig.2015.07.001.

Poullikkas, A. (2005). An overview of current and future sustainable gas turbine technologies. Renewable and Sustainable Energy Reviews, 9(5), 409-443. doi.org/10.1016/j.rser.2004.05.009. 
Sawyer, J. W. (1976). Gas Turbine Engineering Handbook. Gas Turbine Publications; 1976.

Smooth Turbine Maps. (2018). [computer software] [available on www.gasturb.de/software]

Turbocompressor. (2016). Louisiana Chemical Equipment Company. http://www.lcec.com/

\section{Nomenclature:}

$\begin{array}{ll}\text { Symbols: } & \text { Subscripts: } \\ \text { C } & \text { Compressor } \\ \text { C.C } & \text { Combustion Chamber } \\ \text { Con } & \text { Condenser } \\ \text { CT } & \text { Compressor Turbine } \\ \text { D } & \text { Pipeline Diameter }(\mathrm{m}) \\ \text { D.P } & \text { Design point } \\ \text { F } & \text { Fuel-to-Air Ratio } \\ \text { GB } & \text { Gearbox } \\ \text { GT } & \text { Gas Turbine } \\ \text { H } & \text { Pump Head (m) } \\ \text { HV } & \text { Fuel Heating Value }(\mathrm{kJ} / \mathrm{kg}) \\ \text { HRSG } & \text { Heat Recovery Steam Generator } \\ \text { L } & \text { Pipeline Length }(\mathrm{km}) \\ \text { m } & \text { Mass Flow Rate }(\mathrm{kg} / \mathrm{s}) \\ \text { N } & \text { Rotational Speed }(\mathrm{rpm}) \\ \text { p } & \text { Pressure (bar) } \\ \text { PT } & \text { Power Turbine } \\ \text { Q } & \text { Pump volume Flow Rate }\left(\mathrm{m}^{3} / \mathrm{s}\right) \\ \text { R } & \text { Gear Ratio } \\ \text { r } & \text { Pressure Ratio } \\ \text { SFC } & \text { Specific Fuel Consumption }(\mathrm{kg} / \mathrm{kWh}) \\ \text { ST } & \text { Steam Turbine } \\ \text { T } & \text { Temperature }(\mathrm{K}) \\ \text { V } & \text { Velocity }(\mathrm{m} / \mathrm{s}) \\ \text { W } & \text { Work (kW) } \\ \text { z } & \text { Elevation (m) } \\ & \end{array}$

Wang, B., Zhang, H., Yuan, M., Wang, Y., Menezes, B. C., Li, Z., \& Liang, Y. (2019). Sustainable crude oil transportation: Design optimization for pipelines considering thermal and hydraulic energy consumption. Chemical Engineering Research and Design, 151, 23-39. doi.org/10.1016/j.cherd.2019.07.034 a

c

cc

ct

d

dp

$\mathrm{g}$

gb

$\mathrm{gt}$

1

$\mathrm{m}$

$\mathrm{p}$

$\mathrm{pt}$

th

Greek Letters:

$\beta$

$\gamma$

$\varepsilon$

$\eta$

$\mu$

$\rho$

$\omega$

$\Delta$
Ambient

Compressor

Combustion Chamber

Compressor Turbine

Discharge Port

Design Point

Gas

Gear Box

Gas Turbine

Losses

Mechanical

Overall

Pump

Power Turbine

Suction Port

Thermal

Pipeline friction factor Specific gravity $\left(\mathrm{N} / \mathrm{m}^{3}\right)$

Effectiveness

Efficiency

Dynamic Viscosity (Pa.s)

Density $\left(\mathrm{kg} / \mathrm{m}^{3}\right)$

Rotational Speed (rpm)

Change 